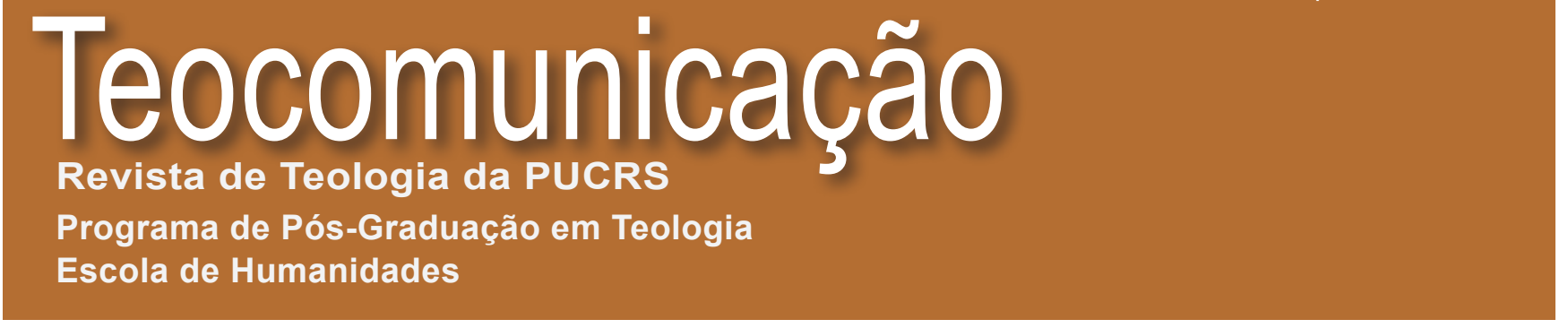

Porto Alegre, v. 48, n. 2, p. 139-148, julho-dezembro 2018

http://dx.doi.org/10.15448/0103-314X.2018.2.32324

Dossiê: LAICATO NA IGREJA E NO MUNDO

\title{
O leigo na Sagrada Escritura
}

\section{The Lay People in the Holy Scripture}

\section{Johan Konings*}

\section{RESUMO}

A significação do laicato na Bíblia pode ser abordada por três vertentes. A primeira é a canônica, que define o leigo como quem não pertence ao clero (e, por extensão, à vida religiosa), abordagem essa que se mostra pouco relevante para o Novo Testamento, a não ser para a compreensão alegórica do sacrifício e do sacerdócio de Cristo, especialmente na Carta aos Hebreus ( $\mathrm{Hb} 4-6$ ). A segunda é a teologia do "povo de Deus, nação sacerdotal", reconhecida na sua fonte veterotestamentária, no Êxodo, na sua releitura neotestamentária, sobretudo na $1^{a}$ Carta de Pedro (1Pd 2,1-12), com múltiplas assonâncias nas demais Escrituras, e na teologia recente, especialmente em torno do Concílio Vaticano II: a vocação batismal ao sacerdócio de todos os fiéis. A terceira vertente, igualmente alimentada pelo Vaticano II e complementar à anterior, é a teologia (e a pastoral) das realidades terrestres ou da secularidade cristã, com seu pano de fundo bíblico na teologia da Criação e da grandeza do ser humano.

Palavras-chave: Laico. Sacerdócio. Secularidade. Santificação. Jesus Cristo.

\section{ABSTRACT}

The meaning of laity in the Bible can be approached from three points of view. The first one is the canonical, which defines the lay person as not belonging to the clergy (and, by extension, to the religious life), an approach that is not relevant to the New Testament, except for the allegorical understanding of sacrifice and priesthood of Christ, especially in the Letter to the Hebrews. The second one is the theology of the "people of God, a sacerdotal nation", recognized in its Old Testament source in the Exodus, in its New Testament re-reading, especially in the First Letter of Peter, with multiple assonances in other Scriptures, and in recent theology, especially around the Second Vatican Council: the baptismal vocation to the priesthood of all faithful. The third strand, which is also nourished by Vatican II and complementary to the previous one, is theology (and pastoral) of earthly realities or Christian secularity, with its biblical background in the theology of Creation and the dignity of the human being. From these considerations follows the understanding of the vocation of all Christians as laity sanctifying the world.

Keywords: Laity. Priesthood. Secularity. Sanctification. Jesus Christ.

\footnotetext{
* Doutor em Teologia pela Universidade Católica de Louvain (Bélgica). Professor de Teologia Bíblica da FAJE - Faculdade Jesuíta de Filosofia e Teologia, em Belo Horizonte.<konings@faculdadejesuita.edu.br>
} 


\section{INTRODUÇÃO}

Quem consulta os dicionários sobre o sentido de "leigo" fica com uma impressão um tanto negativa. O dicionário francês Larousse diz "um cristão que não faz parte do clero", e nosso dicionário Houaiss: "aquele que não recebeu ordens sacras". A primeira edição do monumental Lexikon für Theologie und Kirche (Léxico de Teologia e Igreja), em dez grandes volumes com duas colunas em letra pequena (1930-1938), trazia para o verbete "leigo" a seguinte explicação: leigo é o não clero. O Dicionário Aurélio dá três significados: a. quem não pertence ao clero ou aos religiosos; $b$. que pertence ao povo cristão, como tal, e não à hierarquia; c. que é estranho ou alheio ao assunto. ${ }^{1}$

Por outro lado, na esteira do Iluminismo e da Revolução Francesa, o vocábulo virou característico do laicismo e do Estado laico, apontando para a emancipação, neutralidade ou até inimizade em relação ao clero e à religião como tal.

$\mathrm{O}$ assunto tem atualidade, porque, dentro da Igreja, por um lado, os leigos estão pleiteando maior importância e participação nas decisões da Igreja; e a Hierarquia, por seu lado, procura envolver mais os leigos no dinamismo apostólico. No último século, de fato, cresceu na Igreja a consciência de constituir um corpo com funções diversificadas e um povo com responsabilidades participadas em comunhão. ${ }^{2}$

Quanto ao leigo na Sagrada Escritura, à primeira vista, não haveria muito a dizer, porque não há clero, pelo menos não na comunidade do Novo Testamento, salvo se fizermos uma distinção entre os que ocupam cargos de liderança como os epíscopos (1Tm 3,1-7; Tt 1,6-9); os presbíteros 1Tm 5,17-25; Tt 1,5-9) e o comum dos fiéis. Precisamente isso, porém, nos desafia a esclarecer as raízes do atual entendimento do laicato na Igreja.

\section{LUMEN GENTIUM}

Quando se analisa o texto mais explícito do Concílio Vaticano II sobre os leigos, na Lumen Gentium ( $L G 31$ ), percebe-se o encontro de duas perspectivas: a) primeira é a canônico-institucional (do Direito Canônico), que considera como leigos os que não pertencem ao clero, nem a uma instituição de vida religiosa canonicamente constituída; b) "Por leigos entendem-se aqui todos os cristãos que não são membros da sagrada Ordem ou do estado religioso reconhecido pela Igreja [...]". No sentido abrangente, são todos os batizados e batizadas como membros do povo de Deus:

[...] isto é, os fiéis que, incorporados em Cristo pelo batismo, constituídos em Povo de Deus e tornados participantes, a seu modo, da função sacerdotal, profética e real de Cristo, exercem, pela parte que lhes toca, a missão de todo o Povo cristão na Igreja se no mundo ( $L G 31)$.

Nesta justaposição transparece a tensão que hoje se percebe: por um lado, os leigos são definidos por aquilo que não são, a saber, clero ou membros de uma congregação religiosa; por outro, é-lhes atribuída enorme dignidade (partilhada também pelo clero e pelos religiosos) como membros do povo sacerdotal. Nos anos em torno do Concílio Vaticano II houve, assim, um deslocamento da auto percepção do laicato: de uma percepção institucionalmente negativa e excludente (a não pertença ao clero ou à vida

\footnotetext{
${ }^{1}$ FERREIRA, Aurélio Buarque de Holanda. Leigo. In: Século XXI, O Dicionário da Língua Portuguesa, p. 1197.

2 Esta consciência ganhou importância com a carta encíclica Mystici Corporis de Pio XII em 1943.
} 
religiosa) passou-se a uma percepção positiva, a qual se exprime até hoje, de modo emblemático, em grupos de leigos que reivindicam maior participação nas decisões de governo da Igreja.

Em continuidade, o mesmo no 31 menciona como "vocação específica" dos leigos a responsabilidade secular, as atividades profissionais e os cuidados com a família, que, porém, não é alheia aos outros membros da Igreja.

É própria e peculiar dos leigos a característica secular. Com efeito, os membros da sagrada Ordem, ainda que algumas vezes possam tratar de assuntos seculares, exercendo mesmo uma profissão profana, contudo, em razão da sua vocação específica, destinam-se, sobretudo e expressamente, ao sagrado ministério; enquanto que os religiosos, no seu estado, dão magnífico e privilegiado testemunho de que se não pode transfigurar o mundo e oferecê-lo a Deus sem o espírito das bem-aventuranças.

Observe-se, ainda, que há uma zona cinzenta em torno das religiosas e dos religiosos não clérigos: do ponto de vista canônico, não são clero, mas também não são simples leigos, sendo que gozam de um estatuto e legislação próprios, como vida religiosa consagrada. E coisa análoga pode-se dizer dos institutos seculares e comunidades de vida consagrada.

\section{SACERDOTES, LEVITAS E POVO}

Como dissemos, à primeira vista, a distinção canônica entre clero e religiosos, por um lado, e leigos, por outro, não tem base explícita no Novo Testamento. Existe, porém, um precedente bíblico no Antigo Testamento: os sacerdotes e levitas (cf. $\mathrm{Nm}$ 8,5ss.). É difícil, e também não é o escopo deste artigo, traçar a história dessa instituição. As tradições bíblicas mais antigas mostram que a função sacrifical era exercida não só pelos sacerdotes dos santuários locais, mas também pelos chefes de família, juízes e reis (cf. $\mathrm{Nm}$ 17-18). Por outro lado, sacerdotes eram contratados pelos chefes de clã ou, mais tarde, pelos reis, para serem seus sacerdotes. Eram agregados aos santuários ancestrais de clãs e tribos (Silo, Siquém, Betel) ou, mais tarde, à "cidade de Davi", Sião. Sua função consistia em realizar devidamente os sacrifícios encomendados pelos chefes e o "povo" ( $\mathrm{Hb} 5,1-10 ; 7,1-10)$ distinguindo entre o santo e o profano, o puro e o impuro ( $E z$ 44,23).

É só nos últimos séculos antes de Cristo que os sumos sacerdotes exercem autoridade sobre povo, pelo menos na comunidade étnico-religiosa, porém, sob a tutela dos soberanos estrangeiros persas, gregos e romanos.

Quanto à origem dos "filhos de Levi", sacerdotes que circulavam pelas diversas

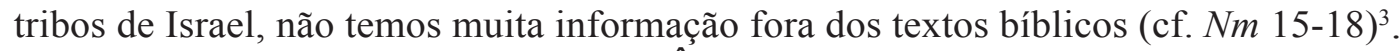
Nos textos bíblicos eles aparecem no Êxodo e no tempo das tribos e, mais tarde, na organização de sacerdotes e levitas em torno do templo de Jerusalém. Esta organização deve ter ocorrido depois da queda e Samaria em 722 a. C., quando muitos sacerdotes do reino do Norte se refugiaram em Judá; e em torno da unificação do culto em Jerusalém, no tempo de Josias, por volta de 620 a. C. Depois do exílio, no período do Segundo Templo, firmou-se a divisão de tarefas que se reflete, sobretudo em Nm 17,16-26. Doravante, os sacerdotes aaronitas são

\footnotetext{
${ }^{3}$ As categorias sacerdotais variavam de acordo com os costumes religiosos dos povos. Em Israel havia a corporação messiânica dos sacerdotes de Melquisedec ( $Z c$ 6,13); os sacerdotes de outras religiões, como os sacerdotes de Potifar (Gn 41,45.50), e outras categorias (Cf. BROWN, DRIVER, AND BRIGGS. Hebrew and English Lexicon of tthe Old Testament, p. 462-464.
} 
encarregados dos sacrifícios e os levitas da manutenção e guarda do templo, bem como do louvor e da música.

Embora essa instituição se tenha dissolvido no início do cristianismo por causa da destruição do templo em 70 d.C., vale destacar brevemente o seu perfil. Se no livro dos Números transparece mais a sua organização - retroprojetada para o tempo do deserto -, em 2 Cr 31,2-21, percebemos sua importância para a vida litúrgica no templo de Salomão. É lhes atribuído, além do sacrifício animal e vegetal, sobretudo o sacrifício do louvor. Inscreve-se nesta visão a tradição dos Salmos, geralmente atribuídos a Davi, considerado como o idealizador do templo, mas também aos cantores levíticos Asaf, Temã e Emã (1Cr 15,16-19). Os Salmos contêm expressões muito profundas da fé e da justiça. Neles, a existência levítica, sem propriedade fundiária, é considerada como viver na "herança" de Deus, o que no grego da Septuaginta se chama klêros (Gn 48,6; 49,14; Lv 16,9). Consoante o Sl 16(15):

Senhor, porção de minha herança e minha taça, tu tens na mão a parte que me cabe.

Para mim as cordas caíram em terrenos aprazíveis; sim, minha herança (LXX: klêronomia) é preciosa para mim (Sl 16,5-6).

A "especialização" sacrifical para oferecer o sacrifício está relacionada, fenomenologicamente falando, à ambivalente percepção do sagrado (ou "numinoso") como "fascinante e tremendo". O contrário do sagrado é o profano (pro = "diante" e fanum = "lugar sagrado; templo"), seria o que está fora do sagrado ou diante do templo, mas fora dele. Profanum é o não consagrado pela religião ${ }^{4}$. Ainda não na Septuaginta ( $3^{\circ}$ séc. a.C.), mas nas traduções gregas ulteriores (Teodocião, Áquila, Símaco) aparece - por exemplo em 1Sm 21,5 - o termo grego bébêlós $s^{5}$ aparece latinizado como laicus (na Vulgata e Nova Vugata) para indicar algo comum, distinto do sagrado. Assim temos um indício de que, no tempo em que nasceu o cristianismo, esse termo podia significar a distinção entre o âmbito do sagrado e o povo em geral. Essa distinção se expressava arquitetonicamente na organização altamente hierarquizada do templo de Jerusalém. $\mathrm{O}$ lugar mais sagrado era o Santo dos Santos, uma espécie de capela (o debîr) acessível somente ao sumo sacerdote uma vez por ano (Ex 31,31; Lv 16,2.29; $H b$ 9,7). Na frente dessa capela havia o Lugar Santo, uma sala maior (o hekal) frequentada por sacerdotes e levitas para o sacrifício do incenso e outras funções litúrgicas. Na frente do Lugar Santo, ao ar livre, havia o átrio dos sacerdotes, onde se encontrava o altar dos sacrifícios animais e vegetais, e, em crescente afastamento, os átrios dos israelitas (os varões), das mulheres e dos gentios.

Já antes de Cristo o templo e os sacrifícios animais estavam sendo "relativizados", quer por uma visão mais ética e espiritual ${ }^{6}$, quer pela prática farisaica de levar alguns ritos do templo até a periferia do judaísmo (o interior da Palestina e a diáspora). Jesus, com seus discípulos, provavelmente não se apresentava como adversário do templo, como às vezes é sugerido, mas inegavelmente o olhava com espírito crítico (a expulsão dos mercadores) e pregava a visão apocalíptica da proximidade de sua destruição (Mc 13,2), palavras lembradas pelos que zombavam de Jesus crucificado (Mc 15,29-30). Além disso, foram os sumos sacerdotes que entregaram Jesus ao poder romano e, quando Pilatos se negou a condená-lo, eles o exigiram como espólio da lei deles (Jo 19,7).

\footnotetext{
${ }^{4}$ SARAIVA, F. R. DOS SANTOS. Novíssimo Dicionário Latino-Português, p. 957.

5 BAUER, Walter. "bébêlos". Wörterbuch zum Neuen Testament, p. 275.

${ }^{6}$ P.ex., $\operatorname{Sr} 35,1-5[1-3]$.
} 
Diversos textos dos evangelhos mostram que a separação entre o profano e o sagrado, segundo os critérios levíticos e farisaicos, não era considerada essencial por Jesus e os seus seguidores (Mc 7,1-23). E enquanto os evangelhos veem em Jesus ressuscitado o novo lugar da presença de Deus, substituindo o templo (Jo 2,20-21), a Carta aos Hebreus coloca Jesus sacrificado, de modo simbólico, no lugar do sacerdote e da vítima sacrifical (Hb 7-10). Para Jesus e seus discípulos o templo e seu sacerdócio pertenciam à ordem do que havia de passar antes que viesse o grande dia do Senhor. Mais tarde, porém, elementos da organização sacerdotal foram reintroduzidos na medida em que o crescimento e a complexificação da Igreja o aconselhavam. Introduziu-se na Igreja a distinção entre os fiéis, em geral, e aqueles que eram ordenados para o ministério do sagrado, distinção que na Idade Média se acentuou por força do modelo feudal, em que as instituições eclesiásticas se configuraram e às vezes se confundiram com a sociedade política.

\section{POVO SACERDOTAL}

A segunda vertente do significado cristão do laicato se inscreve em outro contexto, embora não separado do anterior. Trata-se da expressão "sacerdócio régio, povo santo", aplicada aos batizados, sem distinção, na homilia batismal contida na $1^{\mathrm{a}}$ carta de Pedro. Esta expressão é uma releitura da proclamação da eleição de Israel, segundo Ex 19,3-6:

Moisés subiu ao encontro de Deus. O Senhor o chamou do alto da montanha e disse: "Assim falarás à casa de Jacó e anunciarás aos israelitas: Vistes o que fiz aos egípcios, e como vos levei sobre asas de águia e vos trouxe a mim. Agora, se realmente ouvirdes minha voz e guardardes a minha aliança, sereis minha propriedade entre todos os povos; porque toda a terra é minha, e vós sereis para mim um reino de sacerdotes e uma nação santa. São essas as palavras que falarás aos israelitas".

Em Êxodo, este texto - a eleição - constitui o início da celebração da Aliança do Sinai, a ser completada pela proclamação do Decálogo e do Código da Aliança (Ex 20-23) e encerrada pelo sacrifício da aliança (Ex 24,1-11). O texto de Ex 19 é um texto fundante, que se refere a toda a casa de Jacó (o povo de Israel), e é assim que a primeira carta de Pedro ( $1 P d 2,4-12)$ o aplica, num sentido pleno, a todo o novo povo de Deus, constituído pelos fiéis de Jesus Cristo, marcados pelo batismo.

O "reino de sacerdotes" de que fala Ex 19,6 levanta um problema para a interpretação do texto hebraico ${ }^{7}$. Segundo De Vaux $^{8}$, o sacerdócio evolui e vai assumindo funções específicas junto ao povo de Israel e junto aos santuários para exercer a missão santificadora no mundo. Outra interpretação pensa que "reino de sacerdotes" signifique um povo governado por sacerdotes, uma "hierocracia". Essa diferença de interpretações, porém, não parece influir na interpretação neotestamentária representada pela Carta de Pedro (2,1-12), que, em vez de "reino de sacerdotes", adota a leitura da tradução grega, "sacerdócio régio, povo santo", entendendo que em $1 P d 2,9$ esses atributos se aplicam aos batizados indistintamente:

Vós, ao contrário, sois a geração escolhida, o sacerdócio régio, a nação santa, o povo que ele adquiriu, a fim de que proclameis os grandes feitos daquele que vos chamou das trevas para a sua luz maravilhosa $(1 P d 2,9)$.

\footnotetext{
${ }^{7}$ BROWN, DRIVER, AND BRIGGS. Hebrew and English Lexicon of the Old Testament, p. 463.

8 DE VAUX, R. Le Istituzioni dell'Antico Testamento, p. 342-77.

9 Seria uma marca da "escola sacerdotal" (pós-exílica) no texto de Ex 19,5-6.
} 
Também os versículos precedentes se aplicam, anunciando que eles, com Cristo como pedra angular (Ef 2,20), constituem o novo templo e oferecem os sacrifícios espirituais de sua vida fiel.

"Eis que ponho em Sião uma pedra angular, escolhida e valiosa; quem nela confiar, não será confundido". Para vós, que credes, ela é valiosa! Mas para os que não creem, "a pedra que os construtores rejeitaram tornou-se a pedra angular" e "pedra de tropeço, pedra que faz cair". Eles tropeçam por não crerem à Palavra; essa é a situação deles $(1 P d 2,6-8)$.

A Carta aplica ainda ao povo fiel inteiro a releitura de $O s$ 2,23, que proclama povo de Deus aos que não eram povo e promete a misericórdia aos que não a recebiam: "Vós sois aqueles que antes não éreis povo, agora, porém, sois povo de Deus; os que não tinham alcançado misericórdia, agora, porém, alcançaram misericórdia" $(1 P d 2,10)$. É nestes e noutros textos semelhantes que se baseia a eclesiologia do "novo Povo de Deus", que deixa na sombra a instituição sacerdotal levítico-aaronita.

Também a Carta aos Hebreus ( $H b$ 8-9) relativiza, sob outro viés, a importância do sacerdócio e do culto sacrifical do antigo templo. É considerada como uma exortação a deixar o templo de Sião para trás (não se sabe se ele ainda existia quando a carta foi escrita). A carta mostra que Jesus é agora o único mediador entre nós e Deus, superando o papel de Moisés e também do sumo sacerdote (que até então era a principal autoridade dos piedosos judeus). A parte central da carta é dedicada, especificamente, à superação do sacerdócio e dos sacrifícios da antiga Aliança, em textos que, mediante uma exegese alegórica, mostram Jesus como o verdadeiro sumo sacerdote, não na ordem de Levi e Aarão (pois ele não era da tribo de Levi), mas na ordem de Melquisedec, rei-sacerdote ao qual até Abraão pagou tributo (Gn 14,20). E assim, todos os cristifieis podem, graças a Cristo e seu sacrifício, "aproximar-se" do Santuário, o que até então era privilégio do sumo sacerdote ${ }^{10}$.

Relacionado a isso apresenta-se o tema do sacrifício espiritual. Tanto a primeira carta de Pedro como a carta aos Hebreus recorrem à linguagem figurativa do sacrifício para descrever a vida do cristão.

Do mesmo modo, também vós, como pedras vivas, formai um edifício espiritual, um sacerdócio santo, a fim de oferecerdes sacrifícios espirituais, agradáveis a Deus $(1 P d 2,5)$.

Por meio de Jesus, ofereçamos a Deus um perene sacrifício de louvor, isto é, o fruto dos lábios que celebram o seu nome. Não vos esqueçais da prática do bem e da partilha, pois estes são os sacrifícios que agradam a Deus ( $H b$ 13,15-16).

Esse sacrifício espiritual é o mesmo que a logikê latreia, o culto verdadeiro proposto por Paulo:

Eu vos exorto, irmãos, pela misericórdia de Deus, a oferecerdes vossos corpos em sacrifício vivo, santo e agradável a Deus: este é o vosso verdadeiro culto. Não vos conformeis com este mundo, mas transformai-vos, pela renovação da mente, para que possais distinguir o que é da vontade de Deus, a saber, o que é bom, o que lhe agrada, o que é perfeito $(R m 12,1-2)$.

\footnotetext{
${ }^{10} \mathrm{Cf} . \mathrm{Hb} 7,19.25 ; 12,18.22 .23$. É possível que a Carta aos Hebreus tenha sido dirigida especialmente a membros do sacerdócio judaico para convencê-los de que suas instituições, que eram essencialmente sacrificais, estavam ultrapassadas diante da obra da salvação e reconciliação operada por Cristo.
} 
Não se entendam, portanto, as pneumatikái thysíai $(1 P d 2,5)$ ou a logikê latreia $(R m$ 12,1) como algo imaterial. Pelo contrário, trata-se da prática da vida cristã no mundo, como também sugere Tiago: "Religião pura e sem mancha diante de Deus e Pai é esta: assistir órfãos e viúvas em suas dificuldades e guardar-se da contaminação do mundo" $(T g$ 1,27). Tal é o sacerdócio da vida cristã, exercido na realidade "secular" do mundo.

\section{NO MUNDO, NÃO DO MUNDO}

Ensina a Lumen Gentium a respeito da vocação dos leigos:

Por vocação própria, compete aos leigos procurar o Reino de Deus tratando das realidades temporais e ordenando-as segundo Deus. Vivem no mundo, isto é, em toda e qualquer ocupação e atividade terrena, e nas condições ordinárias da vida familiar e social, com as quais é como que tecida a sua existência. São chamados por Deus para que, aí, exercendo o seu próprio ofício, guiados pelo espírito evangélico, concorram para a santificação do mundo a partir de dentro, como o fermento, e deste modo manifestem Cristo aos outros, antes de mais pelo testemunho da própria vida, pela irradiação da sua fé, esperança e caridade. Portanto, a eles compete especialmente, iluminar e ordenar de tal modo as realidades temporais, a que estão estreitamente ligados, que elas sejam sempre feitas segundo Cristo e progridam e glorifiquem o Criador e Redentor ( $L G 31)$.

Todos os fiéis são chamados a representar a santidade de Deus como povo santo e sacerdotal no "século", termo que neste contexto significa o mundo". $L G 31$ vê nisso o modo específico em que os canonicamente leigos (os não-clero) realizam a santidade de Deus no mundo, sem necessidade de exercer o ministério sacerdotal ordenado ${ }^{12}$. Está claro que se trata de uma missão de todo o povo de Deus e da qual os ministros sagrados não ficam isentos. Pelo contrário, sua missão inclui a atenção pastoral para com a missão "secular" que os leigos têm de assumir. Foi o que entenderam muito bem os padres operários, que optaram por estar juntos do operário leigo, e mesmo do ateu, no mundo como lugar da presença de Deus.

Essa consciência da santidade do mundo - isto é, de sua pertença ao Santo que é Deus - é alimentada pela Bíblia desde a primeira página: Deus viu que sua obra era boa. Exprimem isso os salmos do louvor de Deus na criação (Sl 104) e os textos que evocam a presença da Sabedoria de Deus na criação ( $\operatorname{Pr} 8,22 \mathrm{ss} ; S r$ 24). Ora, esta santidade não é alheia à vocação humana. O ser humano recebe desde o início a vocação de governar a parte da criação que lhe cabe, a título de ser "imagem e semelhança" de Deus (Gn 1,26-28). Poeticamente, “o Adam” é descrito como jardineiro do paraíso de Deus (Gn 2,5-8; Ct 4,12), ${ }^{13} \mathrm{e}$ os salmos cantam sua grandeza acima das demais criaturas:

Quando vejo os teus céus, obra dos teus dedos,

a lua e as estrelas, as coisas que criaste, que é o ser humano, para dele te lembrares, o filho do homem, para que o visites?

$\mathrm{Tu}$ o fizeste pouco menor que os anjos, de glória e de honra o coroaste

e o constituíste acima das obras de tuas mãos. $(S l 2,4-7)$.

\footnotetext{
${ }^{11}$ Saeculum, em latim, significa tanto mundo ou universo como grande espaço de tempo (p.ex., 100 anos).

${ }^{12}$ FERREIRA, Aurélio Buarque de Holanda. "Leigo". In: Século XXI, O Dicionário da Língua Portuguesa.

${ }^{13}$ Pardés em hebraico significa jardim, horto, parque.
} 
É como se Deus tivesse repartido seu trabalho com o ser humano:

Os céus são os céus do Senhor;

a terra, porém, ele a deu aos filhos dos homens $(S l 115,16)$.

Assim, a "secularidade" humana - que não é "secularização" ou "secularismo"14 - é um dom de Deus ("ele a deu"). Ela está inscrita na criação do ser humano e serve de base para a "teologia das realidades terrenas". Esta transparece nos textos conciliares e configurou-se de modo peculiar na teologia da libertação, que privilegia o empenho a favor da justiça e da emancipação político-social, e ensina a ver o mundo e a história não com um olhar distraído passando por cima das contradições e injustiças, mas a partir dos pobres, dos oprimidos e dos excluídos.

\section{EXEMPLOS DE LEIGOS NA BÍBLIA}

Uma separação "de raiz" entre a comunidade e uma "hierocracia" não faz parte do espírito da Bíblia. Os ministros do culto são essencialmente servidores, encarregados de exercer do modo mais adequado os gestos sagrados que exprimem a relação com o Santo de todos os membros da comunidade. Paulo insiste para que os evangelizadores se considerem apenas como "administradores dos mistérios de Deus" (1Cor 4,1). Esses gestos não pertencem a uma casta sacerdotal, mas ao povo como tal, e sua execução é o "serviço do povo", liturgia! O sacerdote levítico presta o serviço do sacrifício para os oferentes, que são o povo.

Os patriarcas não são apresentados como sacerdotes, mas eles exercem a função sacerdotal sem serem apartados para essa função. O mesmo vale para os reis. Moisés, embora da tribo de Levi, não exerce o sacerdócio, que é assumido por seu irmão Aarão. O juiz e profeta Samuel oferece sacrifícios, mas é também um crítico dos abusos do santuário de Silo. O profeta Amós aparece como um leigo total, nem sacerdote nem profeta, enviado a censurar o santuário de Betel. Quem orienta o rei Josias na questão do livro da Lei encontrado no templo é uma mulher, a profetisa Hulda. O administrador leigo, delegado do rei da Pérsia, Neemias, cuida da restauração da cidade e da justiça. Salomão faz a inauguração do templo 1 Rs 8.

O leigo bíblico por excelência é Jesus de Nazaré. Ele não é sacerdote, e nem poderia ser, pois não era da tribo de Levi e sim, de Judá (cf. $H b 8,4)$; como também não pertencia a nenhuma classe superior, nem intelectual, nem econômica. Contudo, não lhe faltava autoridade, inclusive quanto ao domínio do sagrado, e isso se confirmava pelo poder que exercia sobre o "anti-santo", os demônios. Judeu comum, próximo do povo simples, era piedoso, mas também crítico em relação aos abusos no templo, o que parece ter sido, como já dissemos, o ensejo imediato para sua condenação.

Decisivo para a memória eclesial foi que, segundo a narrativa da Última Ceia, ele interpretou sua morte como o sacrifício da nova Aliança em seu sangue (Mc 14,24, Lc 22,20). Sua palavra na Ceia é uma clara referência ao sacrifício da Aliança que confirmava Israel como povo de Deus (Ex 24, 1-11, cf. 19,3-6). Além disso, representa também o sentido pleno da figura do Servo Padecente. Seu sangue - símbolo da vida, mas também da morte sangrenta - é derramado "pelos muitos" (cf. Is 53,12).

Esta associação da morte de Jesus ao sacrifício da nova Aliança tem um eco na aplicação a Jesus da terminologia sacrifical como sacrifício de expiação dos

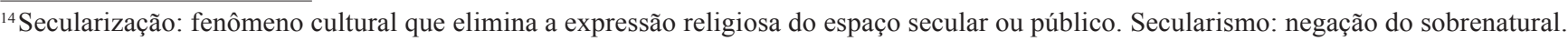


pecados (Hb 9-10; 1 Jo 2,2; 4,10). Assim, Jesus é o sacerdote que santifica a humanidade pelo dom de sua vida até a morte sangrenta, a qual lembra os sacrifícios de expiação nos quais o sangue, símbolo de vida e morte, ocupava um papel indispensável. Em linguagem "platônica", $H b 7$ apresenta o sacerdócio aaronítico como a "sombra" terrena do sacerdócio superior sugerido pela narrativa de Abraão e Melquisedec, à qual alude o $S l$ 110,4. O sacerdócio melquisedequiano não supõe o sacerdócio aaronita. Jesus é aaroniticamente leigo em seu viver e morrer, mas realiza uma consagração superior pela dedicação de sua vida e a dos seus amados a Deus, até o fim.

O cap. 17 de João, apresenta a "oração sacerdotal", situada na despedida de Jesus deste mundo, apresenta Jesus como o sacerdote que dedica a Deus ("consagra") sua própria vida para que sejam assim consagrados os que estão em comunhão com ele $\left(J_{o} 17,19\right)$. Assim, Jesus pode ser chamado o sacerdote da nova Aliança pela doação de sua vida e morte em prol da multidão humana, representada, na Última Ceia, pelos doze que significam o povo todo, não só o antigo povo das doze tribos, mas toda a ekklêsía chamada a constituir o novo povo de Deus.

\section{CONCLUSÃO}

Confirma-se a visão de Lumen Gentium no 31 . Os cristãos, todos eles, são o povo remido enquanto povo da nova Aliança e adquirido para Deus por Jesus Cristo. É um povo "secular" no sentido de sua missão no mundo criado, segundo a visão de Gn 1,26-28; Sl 8; Sl 115,16 e outros textos. Ao mesmo tempo, é povo "sacerdotal" no sentido da Nova Aliança, povo que encarna o Reinado de Deus no mundo.

Quando se discute a participação dos leigos na Igreja com instituição convém distinguir entre governo ou administração e organização litúrgico-sacramental. É bom lembrar que nem mesmo no Israel clássico o sacerdócio era uma função de governo, mas sim, um serviço ao povo para seus fins litúrgicos. Participação em governo e administração não é a mesma coisa que participação no serviço ministerial do culto, o "ministério (do) sagrado". No nível da união com Cristo, todos são "laicais" como membros do novo povo sacerdotal que exerce a missão santificadora no mundo (1Cor 12,12-30; Cl 1,15-20). É impossível tirar daí critérios imediatos para o ministério sagrado especificamente. Por outro lado, na hora de estabelecer funções específicas para o ministério sagrado dentro da Igreja, convém que a dignidade sacerdotal em Cristo de todos os fiéis se reflita nessa instituição, pela ausência de discriminação, ou seja, de distinções que não se justificam pelas exigências próprias dos serviços atribuídos. Ultimamente, pudemos aplaudir a integração de mulheres em funções administrativas do mais alto escalão eclesiástico. Quanto à admissão ao sacramento da Ordem, porém, percebem-se reticências, baseadas sobretudo no argumento de que o sacerdote atua "in persona Christi”. Embora isso deva ser entendido no sentido de que ele é instrumento e não autor da ação sacramental ${ }^{15}$, julga-se que a imagem simbólica de Cristo masculino deve ser preservada na presidência da Eucaristia. Entretanto, muitos consideram que isso não impede a admissão de mulheres ao diaconato. Em todo o caso, enquanto essa questão continua suspensa, pode-se dizer, sem dúvida, que a ordem sacramental deve promover e não dificultar o "aproximar-se do Santuário" preconizado pela Carta aos Hebreus, como de fato se confirma nas gradativas aberturas que a Igreja vem praticando desde a promoção da comunhão eucarística frequente até nossos dias.

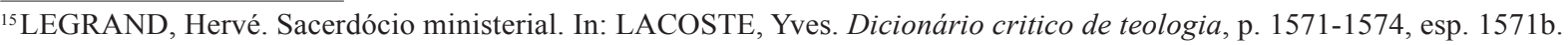


Importante é que todos estejam unidos na comunhão da obra de Cristo e que a laicalidade seja compreendida como "secularidade santificadora", como sugeriu, faz quase um século, o fundador da Juventude Operária Católica, o jovem padre Joseph Cardijn (mais tarde levado ao cardinalato pelo papa Paulo VI), quando disse que o altar do operário é seu balcão de ferramentas.

\section{REFERÊNCIAS}

BAUER, Walter. “bébêlos”. In: Wörterbuch zum Neuen Testament. Berlin; New York: Walter de Gruyter, 1971.

BROWN; DRIVER; BRIGGS. Hebrew and English Lexicon of the Old Testament. Lafayete: Associate Publishers and Autors, 1981.

CONCÍLIO ECUMÊNICO VATICANO II. Constituição Dogmática Lumen gentium sobre a Igreja (21.11.1964). São Paulo: Paulus, 1997.

DE VAUX, Roland. Le Istituzioni dell'Antico Testamento. Milano: Marietti, 1977.

FERREIRA, Aurélio Buarque de Holanda. Leigo. In: Século XXI, O Dicionário da Língua Portuguesa. 4⿳亠丷 impressão. Rio de Janeiro: Nova Fronteira, 1999.

LEGRAND, Hervé. Sacerdócio ministerial. In: LACOSTE, Yves. Dicionário crítico de teologia. São Paulo: Loyola, 2004. p. 1571-1574.

SARAIVA, F. R. dos Santos. "Profanus”. In: Novíssimo Dicionário Latino-Português. Rio de Janeiro: Livraria Garnier, 1993.

ZORELL, F. Lexicon Hebraicu et Aramaicum Veteris Testamenti. Roma: Pontificium Institutum Biblicum, 1968.

Recebido em: 25/10/2018

Aprovado em: 03/12/2018

\section{Correspondência para:}

Prof. Dr. Johan Konings

Faculdade Jesuíta de Filosofia e Teologia

Av. Dr. Cristiano Guimarães, 2127 - Planalto

CEP 31720-300 Belo Horizonte, MG, Brasil 